\title{
1 Monitoring the combined effects of drought and salinity stress on 2 crops using remote sensing
}

Abstract. Global sustainable agricultural systems are under threat, due to projected increases of co-occurring drought and salinity with climate change. Combined effects of drought and salinity on agricultural crops have traditionally been evaluated in small-scale experimental studies. As such the need exists for large scale studies that increase our understanding and assessment of the combined impacts in agricultural practice in real life scenarios. This study aims to provide a new approach to estimate and compare the impacts of drought, salinity and their combination on crop traits at large spatial $\left(138.74 \mathrm{~km}^{2}\right)$ and temporal extents in the Netherlands using remote sensing observations. Specifically, for both maize and potato, we calculated five functional traits from Sentinel-2 observations, namely: leaf area index (LAI), the fraction of absorbed photosynthetically active radiation (FAPAR), the fraction of vegetation cover (FVC), leaf chlorophyll content $(\mathrm{Cab})$ and leaf water content $(\mathrm{Cw})$. Individual and combined effects of the stresses on the seasonal dynamics in crop traits were determined using both one-way and two-way ANOVAs. We found that both stresses (individual and co-occurring) affected the functional traits of both crops significantly (with $\mathrm{R}^{2}$ ranging from 0.326 to 0.796 ), though with stronger sensitivities to drought than to salinity. While we found exacerbating effects within co-occurrent stresses, the impact-level depended strongly on the moment in the growing season. For both crops, LAI, FAPAR and FVC dropped the most under severe drought stress conditions. The patterns for $\mathrm{Cab}$ and $\mathrm{CW}$ were more inhibited by co-occurring drought and salinity. Consequently, our study constitutes a way towards evaluating drought and salinity impacts in agriculture with the possibility of potential large-scale application for a sustainable food security.

Keywords: Drought; Salinity; Agriculture; Remote sensing; Functional traits

\section{Introduction}

Food production is required to increase by $70 \%$ to satisfy the growing population demand by the year 2050 (Godfray et al., 2010). Meanwhile, food security is becoming increasingly threatened due to the increasing abiotic stresses under the influence of global climate change. Currently, abiotic stresses, including drought, soil salinity, nutrient stress and heavy metals, are estimated to constrain crop productivity by $50 \% \sim 80 \%$ (Shinozaki et al., 2015). Of these stresses, drought and salinity have been identified as the two main factors to limit crop growth, affecting respectively $40 \%$ and $11 \%$ of the global irrigated areas (FAO, 2020;Dunn et al., 2020). With drought and salinity forecasted to increase spatially and in severity (Schwalm et al., 2017; Trenberth et al., 2013;Rozema and Flowers, 2008), and with predictions of higher co-occurrence around the world (Wang et al., 2013;Corwin, 2020; Jones and van Vliet, 2018), food production will be deeper challenged by both stresses.

Numerous small-scale experimental studies for a large variety of crops have shown that the impact of co-occurring drought and salinity stress is additive. It was found that co-occurrence of drought and salinity stress decreased the yield of spinach (Ors and Suarez, 2017) and of the forage grass Panicum antidotale (Hussain et al., 2020) more than compared with the 
occurrence of one of these stresses only. Likewise, cotton root growth was observed to be more inhibited under the cooccurrence of drought and water stress than by isolated occurrences (Zhang et al., 2013). Similarly, the exacerbating effect of co-occurring stresses has been shown to limit both maize reproductive growth and grain formation (Liao et al., 2022). While these small-scale experimental studies demonstrate the exacerbating effects of drought and salinity, they have limitations in projecting the impact towards real farmers' conditions due to their small-scale experimental nature. Thus, research focusing on the combined impacts of drought and salinity with respect to large-scale evaluation is still a knowledge gap.

Remote sensing (RS) provides a huge potential to close this knowledge gap due to its capability of monitoring continuous large areas at a frequent interval. Traditionally, remote sensing has used vegetation indices, such as Normalized Difference Vegetation Index (NDVI) (Tucker, 1979), to monitor the impact on crop growth. Nevertheless, such indices provide limited information on how this impact is achieved (e.g. Wen et al., 2020) and how it can be mitigated. With the launch of better multispectral and high-resolution satellite sensors (such as Sentinel-2), new RS methods (e.g., hyperspectral, thermal infrared, microwave) have been identified to detect stress in both natural vegetation (Gerhards et al., 2019; Vereecken et al., 2012) as well as for agricultural applications (Homolova et al., 2013;Weiss et al., 2020). Specifically, these new RS methods allow for the retrieval of plant traits that directly link to plant processes, such as leaf biochemistry and photosynthetic processes, and thereby provide high potential for agricultural applications. RS plant traits of specific interest to monitor crop health include: leaf area index (LAI) (Wengert et al., 2021), canopy chlorophyll content (Cab*LAI) (Gitelson et al., 2005), canopy water content (Cw*LAI) (Kriston-Vizi et al., 2008), the fraction of absorbed photosynthetically active radiation (FAPAR) (Zhang et al., 2015), and the fraction of vegetation cover (FVC) (Yang et al., 2018). However, while there have been several attempts to monitor the response of crop health based on a multi-trait, multicrop, and either drought or salinity focus, not much research has taken these three factors into account simultaneously (Wen et al., 2020).

In this study, we propose a novel approach to estimate, compare and evaluate the impacts of drought, salinity, and their combination on crop traits using remote sensing. A stress co-occurrence map was created by overlaying a high-resolution drought map of 2018 with a groundwater salinity map. Then, we characterized the response of maize and potato to different stress conditions based on five plants traits (LAI, FAPAR, FVC, Cab and Cw). Two-way ANOVAs were adopted to test the main effects and the interactive effect between stress combinations and time on crop traits. Moreover, the effect of drought and salinity on crop traits was determined across the growing season with one-way ANOVAs. Consequently, this approach facilitates simultaneously monitoring crop health at various scales (regional, national, continental) across multiple stresses (drought, salinity) and multiple species.

\section{Methodology}

To achieve our aim of monitoring the impacts of (co-occurring) drought and salinity on agricultural production, we developed a new approach to estimate crop traits from remote sensing observations. Specifically, we developed an approach that integrates image-processing techniques, such as image classification, co-registration, land surface parameter retrieval, and time-series analysis. Using these techniques, we were able to estimate the drought, salinity and vegetation growth. 

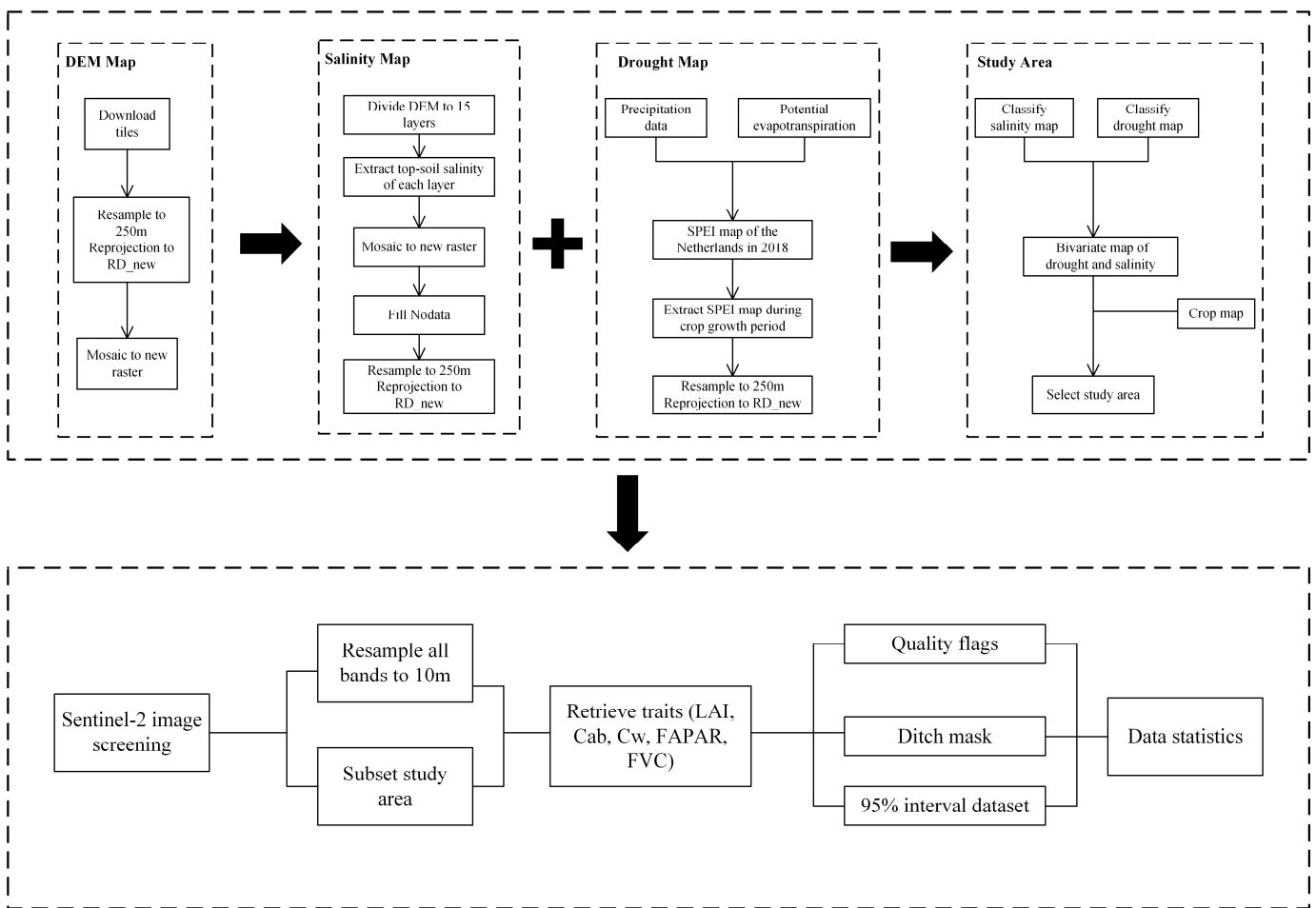

Figure 1. Technical workflow of the maps and data framework.

To allow for a detailed evaluation, we focused on the 2018 summer drought in the Netherlands. This period was selected because of the extreme drought that affected a large part of Europe (Masante D., 2018). Within parts of the selected area salinity was reported to increase during that same period (Broekhuizen, 2018). Hence this study area provides us with the opportunity to investigate the combined impacts of these stresses on crops. In the following paragraphs, we provide more information on the specific processing steps.

\subsection{Study area and data}

\subsubsection{Drought map}

A drought map of the Netherlands in 2018 was created based on the standardized precipitation evapotranspiration index (SPEI) drought index, which was calculated from long-term precipitation data and potential evapotranspiration, from 2004 to 2018 (Chen et al., 2021). Specifically, SPEI was estimated using a 3-month sliding time window, as this found best to investigate the impacts on the local ecosystems. We have extracted SPEI-3 data from April 1st to October 30 th, totally 214 days, as this coincided with the crop growth period of both maize and potato. Then, the drought map was resampled to $250 \mathrm{~m}$ resolution using the nearest neighbor interpolation and reprojected to RD_new projection. Finally, the drought map was classified into three classes namely no drought (SPEI from-214 to 0), moderate drought (SPEI from -321 to -214), and severe drought (SPEI < =-321) (McKee et al., 1993) (Fig. 2a).

\subsubsection{Salinity map}


A topsoil salinity map of the Netherlands was created based on a nationwide fresh-salt groundwater dataset, which derived chloride concentrations as salinity indicator (https://data.nhi.nu/). To obtain the topsoil salinity map, 15 layers of the groundwater salinity were extracted from the 3D groundwater salinity map. For each location, the layer closest to the corresponding to location's elevation (according to the Digital Elevation Model), i.e. closest to the soil surface, was selected. The salinity map was resampled to $250 \mathrm{~m}$ resolution and reprojected to RD_new projection. Ultimately, the salinity map was classified into three levels namely no-salinity $\left(0.1 \mathrm{~g} \cdot \mathrm{L}^{-1}\right.$ to $\left.0.8 \mathrm{~g} \cdot \mathrm{L}^{-1}\right)$, moderate salinity $(0.8 \mathrm{~g} \cdot \mathrm{L}-1$ to 2.5 $\left.\mathrm{g} \cdot \mathrm{L}^{-1}\right)$, severe salinity $\left(>=2.5 \mathrm{~g} \cdot \mathrm{L}^{-1}\right)$ according to the salt-resistant capacity of various crops cultivated in the Netherlands (Mulder et al., 2018;Stuyt, 2016) (Fig. 2b).

\subsubsection{Crop map}

The crop map of the Netherlands in 2018 was collected from the Key Register of Parcels (BRP) of the Netherlands Enterprise Agency (https://www.pdok.nl/introductie/-/article/basisregistratie-gewaspercelen-brp-). The crop map was resampled to $250 \mathrm{~m}$ resolution and reprojected to $\mathrm{RD}$ new projection.

\subsubsection{Co-occurrence map of drought and salinity}

The drought map and the salinity map were overlain to evaluate co-occurrences of drought and salinity of the Netherlands in 2018 (Fig. 2c). By classifying the three stress levels for the individual occurrences, we obtained nine stress classes of co-occurring drought and salinity, namely no stress, moderate drought only (MD), severe drought only (SD), moderate salinity only (MS), severe salinity only (SS), moderate drought and moderate salinity (MD+MS), moderate drought and severe salinity (MD+SS), severe drought and moderate salinity (SD+MS), and severe drought and severe salinity (SD+SS).

(a)

)

(5)

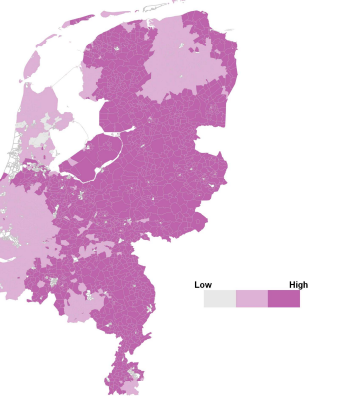

\section{(b)}

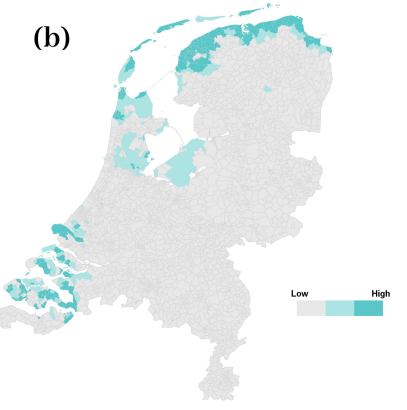

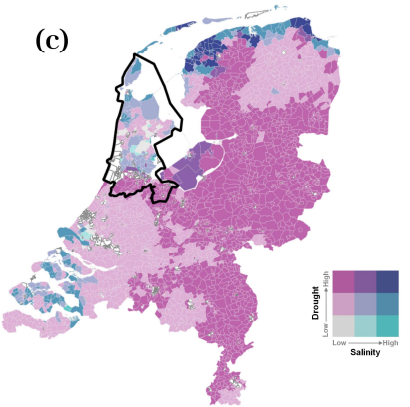

Figure 2. The overlap map of a) drought and b) salinity in the Netherlands to show c) co-occurrence of drought and salinity. The selected study area is indicated by black lines in panel $\mathrm{c}$.

\subsubsection{Study area selection}

Based on the national map of the Netherlands (Fig. 2c), a single region with similar soil type, climate, tillage systems, and irrigation methods was chosen to minimize the interference of these factors on the observed trait expressions. The province of North-Holland was selected because it contained the most (7 out of 9) combinations of drought and salt stress (Fig. 2c), namely: no stress, MD, SD, MS, SS, MD+MS, and SD+SS. Moreover, both maize and potato were cultivated across all stress combinations in this province. For further analysis, MS and SS were grouped into a new class of salinity stress since the area of MS and SS was quite limited. Therefore, six classes of stress combinations namely no stress, MD, SD, salinity (MS+SS), MD+MS, and MD+SS were analyzed for the study area. 


\subsection{Traits retrieval}

\subsubsection{Satellite data}

Eight cloud-free scenes were found (21/04/2018, 06/05/2018, 26/05/2018, 30/06/2018, 15/07/2018, 13/09/2018, $13 / 10 / 2018$, and 28/10/2018) to cover the crop growth cycle. In prior analyses, we found that none of the scenes in August $(04 / 08 / 2018,09 / 08 / 2018,14 / 08 / 2018,19 / 08 / 2018,24 / 08 / 2018$, and 29/08/2018) was of high quality, i.e. with low cloudcover, and we therefore choose to omit August from our analysis. After this prior analysis, we downloaded Level 2A (L2A) data from The Copernicus Open Access Hub (https://scihub.copernicus.eu/). Then, bands in $20 \mathrm{~m}$ and $60 \mathrm{~m}$ resolution were resampled to $10 \mathrm{~m}$ resolution to match consistency for traits retrieval.

\subsubsection{Traits selection}

Plant traits were selected in consideration of their corresponding impacts on crop functioning and their potential for assessment by remote sensing. LAI is a critical vegetation structural trait related to various plant functioning processes such as primary productivity, photosynthesis, and transpiration (Jarlan et al., 2008;Asner et al., 2003;Boussetta et al., 2012; Fang et al., 2019). FAPAR depends on vegetation structure, energy exchange, and illumination conditions while FAPAR is also an important parameter to assess primary productivity (Liang, 2020; Weiss and Baret, 2016). FVC is a promising parameter corresponding to the energy balance process such as temperature and evapotranspiration (Weiss and Baret, 2016). Cab is an effective indicator of stress and is strongly related to photosynthesis and resource strategy (Croft et al., 2017). Cw plays an important role in transpiration, stomatal conductance, photosynthesis and respiration (Bowman, 1989; Zhu et al., 2017), as well as in drought assessment (Steidle Neto et al., 2017).

\section{3 dataset processing}

The biophysical processor of Sentinel Application Platform (SNAP) was used to compute the selected canopy traits (LAI, FAPAR, FVC, Cab*LAI, and Cw*LAI) for each pixel from the Sentinel-2 top of canopy reflectance data. This biophysical processor is driven by an artificial neural network (ANN) approach, trained using the PROSAIL simulated database (Weiss and Baret, 2016). To eliminate the effects of crop biomass on canopy levels of chlorophyll and water, they were expressed as their leaf content counterparts, namely $\mathrm{Cab}$ (='Cab*LAI' / LAI) and Cw (='Cw*LAI' / LAI).

Pixels with quality flags were eliminated from the dataset. It was observed that in April no crop had yet been planted. Instead, we observed that only along the edge of the plots, e.g. in ditches, vegetation was found. This feature was used to generate a ditch map and to mask out pixels in trait maps for the other months. For each variable and each date, only data within the $95 \%$ confidence interval were taken to increase data robustness.

\subsection{Analysis}

Due to the unbalance in the occurrence of stress conditions, drought and salinity were not considered as two independent factors. Instead two-way ANOVAs were adopted to test the main effects and the interactive effect between stress combinations (consisting of 6 levels) and time (5 months) on crop traits. Significant effects of the main stress condition were investigated through post hoc tests to test whether interaction effects between drought and salinity had occurred. Twoway ANOVAs were run separately for each trait and each crop type (maize and potato) as we expected different patterns. In the Netherlands, potato and maize are planted between mid-April to early May. Crops are surfacing in May and harvested in October. Therefore, to evaluate the response of crops to stresses across the growing season, the effect of drought and salinity on crop traits was determined for May, June, July, and September with a one-way ANOVA. Tukey HSD post hoc 
tests were performed to identify the differences among the six stress combinations. All statistical analyses were performed with SPSS 27.0 (SPSS Inc., USA).

\section{Results}

\subsection{Stress impacts depend on moment in growing season}

The two-way ANOVAs revealed strong effects of date and stress level on the five traits with effect sizes of the response $\left(\mathrm{R}^{2}\right)$ ranging from 0.326 to 0.796 for the five traits, which was similar for maize and potato. For both maize and potato, $\mathrm{R}^{2}$ values were lowest for $\mathrm{Cab}$ and highest for LAI, FAPAR and FVC. For maize, we found a significant main effect of both date and stress $(p<0.05)$ for Cab, Cw, FAPAR, and FVC. In contrast, LAI was not significantly different across the different stress conditions. For potato, all main effects of date and stress were significant for all five crop traits (Table 1). For all traits and both crops, the interaction between the effects of time and stress conditions was significant $(p<0.05)$ (Table 1), indicating that the impact of stress depended on the moment in the growing season. Despite the significant interaction terms, the partial Eta squared values (Table 1) show that the effects of time in the growing season were much stronger than those of stress or the interaction of date and stress. The effects of date for maize were stronger than for potato. Interestingly, the effects of the interaction between date and stress were stronger than those of the main effects of stress, suggesting strongly time-specific impacts of stress on the crop traits investigated. The interaction terms were strongest for FVC.

Table 1. Two-way ANOVA for different crop traits by time series and stress interactions.

\begin{tabular}{|c|c|c|c|c|c|c|}
\hline Crops & Traits & Factors & $\mathrm{F}$ & $p$ & $\begin{array}{c}\text { Partial Eta } \\
\text { Squared }\end{array}$ & $\mathrm{R}^{2}$ \\
\hline \multirow{15}{*}{ Maize } & \multirow{3}{*}{ LAI } & date & 2144.5 & 0.000 & 0.636 & \multirow{3}{*}{0.766} \\
\hline & & stress & 1.4 & 0.226 & 0.001 & \\
\hline & & date*stress & 8.5 & 0.000 & 0.033 & \\
\hline & \multirow{3}{*}{$\mathrm{Cab}$} & date & 333.9 & 0.000 & 0.222 & \multirow{3}{*}{0.326} \\
\hline & & stress & 10.7 & 0.000 & 0.008 & \\
\hline & & date*stress & 3.6 & 0.000 & 0.015 & \\
\hline & \multirow{3}{*}{$\mathrm{Cw}$} & date & 952.1 & 0.000 & 0.449 & \multirow{3}{*}{0.590} \\
\hline & & stress & 9.9 & 0.000 & 0.007 & \\
\hline & & date*stress & 4.0 & 0.000 & 0.017 & \\
\hline & \multirow{3}{*}{ FAPAR } & date & 1865.9 & 0.005 & 0.603 & \multirow{3}{*}{0.738} \\
\hline & & stress & 3.3 & 0.000 & 0.002 & \\
\hline & & date*stress & 8.5 & 0.000 & 0.033 & \\
\hline & \multirow{3}{*}{ FVC } & date & 2022.5 & 0.000 & 0.622 & \multirow{3}{*}{0.761} \\
\hline & & stress & 22.1 & 0.000 & 0.015 & \\
\hline & & date*stress & 28.7 & 0.000 & 0.105 & \\
\hline \multirow{11}{*}{ Potato } & \multirow{3}{*}{ LAI } & date & 752.1 & 0.000 & 0.273 & \multirow{3}{*}{0.782} \\
\hline & & stress & 13.7 & 0.000 & 0.006 & \\
\hline & & date*stress & 8.1 & 0.000 & 0.020 & \\
\hline & \multirow{3}{*}{$\mathrm{Cab}$} & date & 96.4 & 0.000 & 0.050 & \multirow{3}{*}{0.329} \\
\hline & & stress & 54.2 & 0.000 & 0.024 & \\
\hline & & date*stress & 8.7 & 0.000 & 0.023 & \\
\hline & \multirow{3}{*}{$\mathrm{Cw}$} & date & 347.4 & 0.000 & 0.158 & \multirow{3}{*}{0.571} \\
\hline & & stress & 68.1 & 0.000 & 0.030 & \\
\hline & & date*stress & 10.3 & 0.000 & 0.027 & \\
\hline & \multirow{2}{*}{ FAPAR } & date & 612.7 & 0.000 & 0.234 & \multirow{2}{*}{0.744} \\
\hline & & stress & 25.8 & 0.000 & 0.011 & \\
\hline
\end{tabular}




\begin{tabular}{lcllll} 
& date*stress & 14.0 & 0.000 & 0.034 & \\
\hline \multirow{3}{*}{ FVC } & date & 844.0 & 0.000 & 0.297 & \\
& stress & 18.8 & 0.000 & 0.008 & 0.796 \\
& date*stress & 13.6 & 0.000 & 0.033 &
\end{tabular}

\subsection{Response of LAI, FAPAR, FVC to drought and salinity}

Given the significance of both date and stress and their interactions, subsequent one-way ANOVAs were performed to compare the effects of drought and salinity on LAI, FAPAR, and FVC for maize and potato in May, June, July, and September separately (Fig. 3). The patterns for LAI, FAPAR and FVC were very similar, although they differ in details and are therefore treated together.

For maize, LAI had the lowest $(p<0.05)$ value under severe drought (SD) conditions while both FAPAR and FVC obtained their lowest value under MD+SS stress conditions in May. In June, both LAI and FVC dropped the most under salinity stress and it was significantly $(p<0.05)$ different from MD, MD+MS, and MD+SS conditions, but not significantly different from no stress conditions. In contrast, FAPAR also reached its the lowest value (under MD+MS stress conditions) in June but had a significant difference $(p<0.05)$ compared with no stress conditions. Both in July and September, LAI, FAPAR, and FVC all had the lowest value under SD conditions, and the difference was significant compared with no stress conditions.

For potato, LAI, FAPAR, and FVC had the lowest $(p<0.05)$ value under MD+MS and MD+SS stress conditions. In June, LAI, FAPAR as well as FVC reached the lowest value under SD conditions and were significantly lower than in most other stress conditions even though the difference was not significant from no stress conditions. In July, there was a tendency for LAI, FAPAR and FVC to be lower at stress conditions, although none of the effects were significant. In September, however, LAI, FAPAR and FVC significantly decreased under MD, MD+MS, and MD+SS conditions, and the difference was significant compared with no stress conditions. In addition, the difference was not significant among these three stress conditions.

Therefore, both for maize and potato, LAI, FAPAR and FVC dropped the most under SD stress conditions when they reached their respective maximum value, compared with other stress conditions. At the same time, maize and potato were more sensitive to drought than salinity since no significant change was observed between drought conditions and conditions with a combination of drought and salinity stress. 
(a)
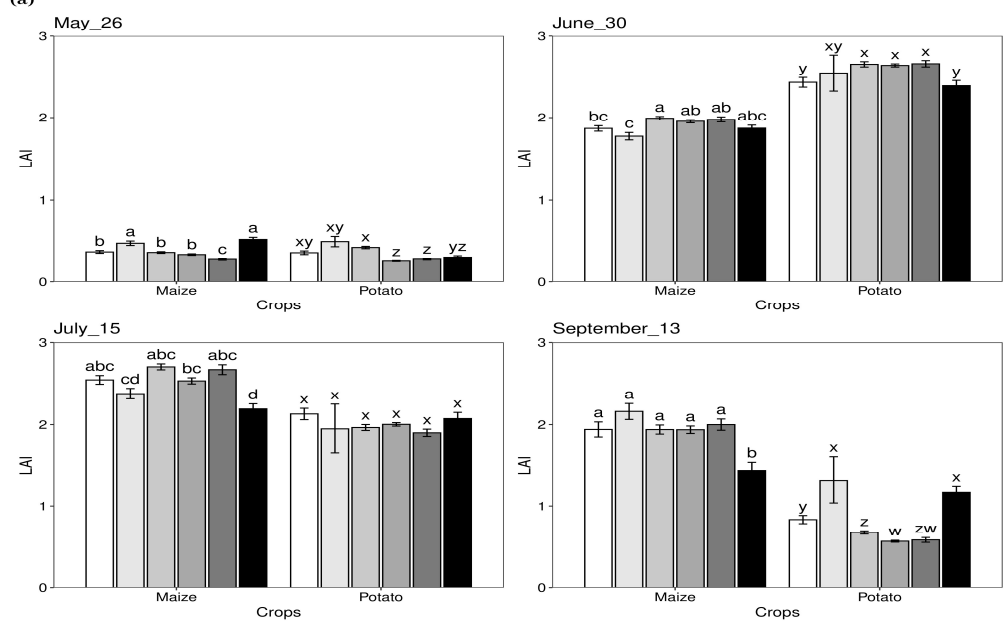

(b)
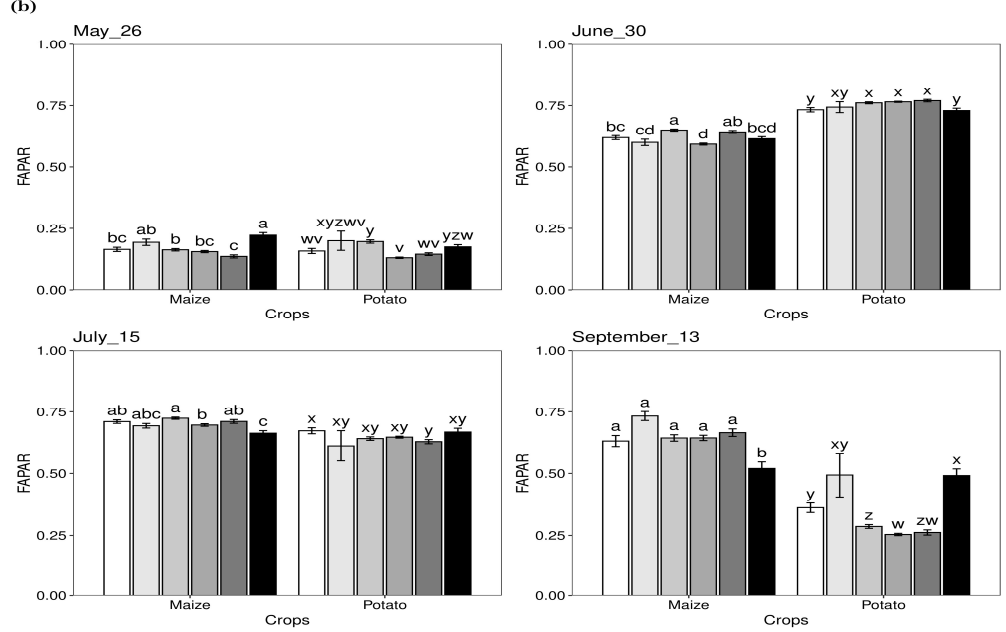

(c)
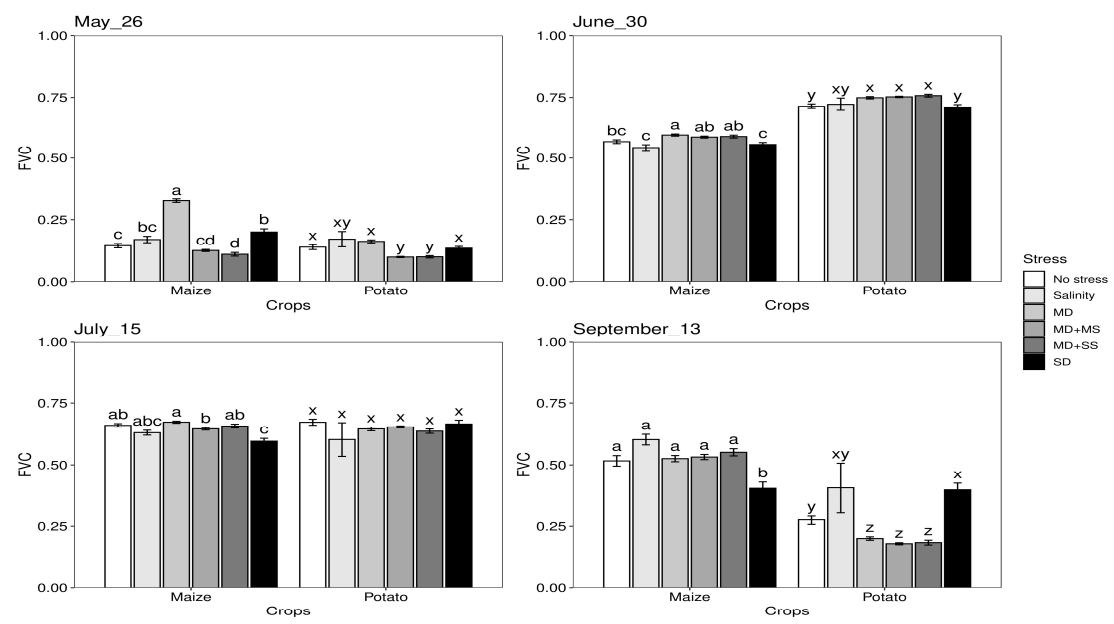
Figure 3. Expressions of LAI, FAPAR and FVC under various stress conditions in May, June, July and September. Different letters in each panel indicate significant differences $(p<0.05)$.

\subsection{Response of leaf chlorophyll and water content to drought and salinity}

The one-way ANOVAs revealed that there were significant $(p<0.05)$ impacts of the various stress conditions on Cab and $\mathrm{Cw}$ (Fig. 4). For maize, Cab obtained its lowest value under salinity stress in May and June while it was not significantly different from no stress conditions. However, in July, Cab reached the lowest value under MS+MS conditions although the difference was not significant from other stress conditions. There were no significant changes observed for Cab in September. For potato, Cab dropped the most under saline conditions in May although the difference was not significant from no stress conditions. Furthermore, Cab significantly decreased under MD+SS conditions in June and July, compared with other conditions. Although Cab dropped the most under salinity conditions in September, the difference was not significantly different from other conditions. In addition, compared with no stress, potato had the lowest Cab under MD+SS conditions while there was no significant difference between MD+SS and saline conditions only.

$\mathrm{Cw}$ decreased under all stress conditions in May, June and July for both maize and potato, except for SD conditions in May, compared with no stress conditions. At the same time, $\mathrm{Cw}$ reached its lowest value under $\mathrm{MD}+\mathrm{SS}$ co-occurring conditions and it was significantly different from under no stress conditions. Nonetheless, there were different changes for both maize and potato in September. $\mathrm{Cw}$ was not significantly different among any condition for maize while it was the lowest under salinity conditions for potato.

Therefore, this analysis illustrates that salinity affected maize less than drought since crop responses were more obvious to drought than salinity for $\mathrm{Cab}$ and $\mathrm{Cw}$. In contrast, salinity showed a more severe effect on maize and potato at the early growth stages for Cab. Meanwhile, Cab was affected by co-occurring drought and salinity in June and July for potato. It seems that there was a non-additive effect of drought and salinity, since the changes were not significant between MD conditions, salinity, and MD+MS compared to no stress conditions.
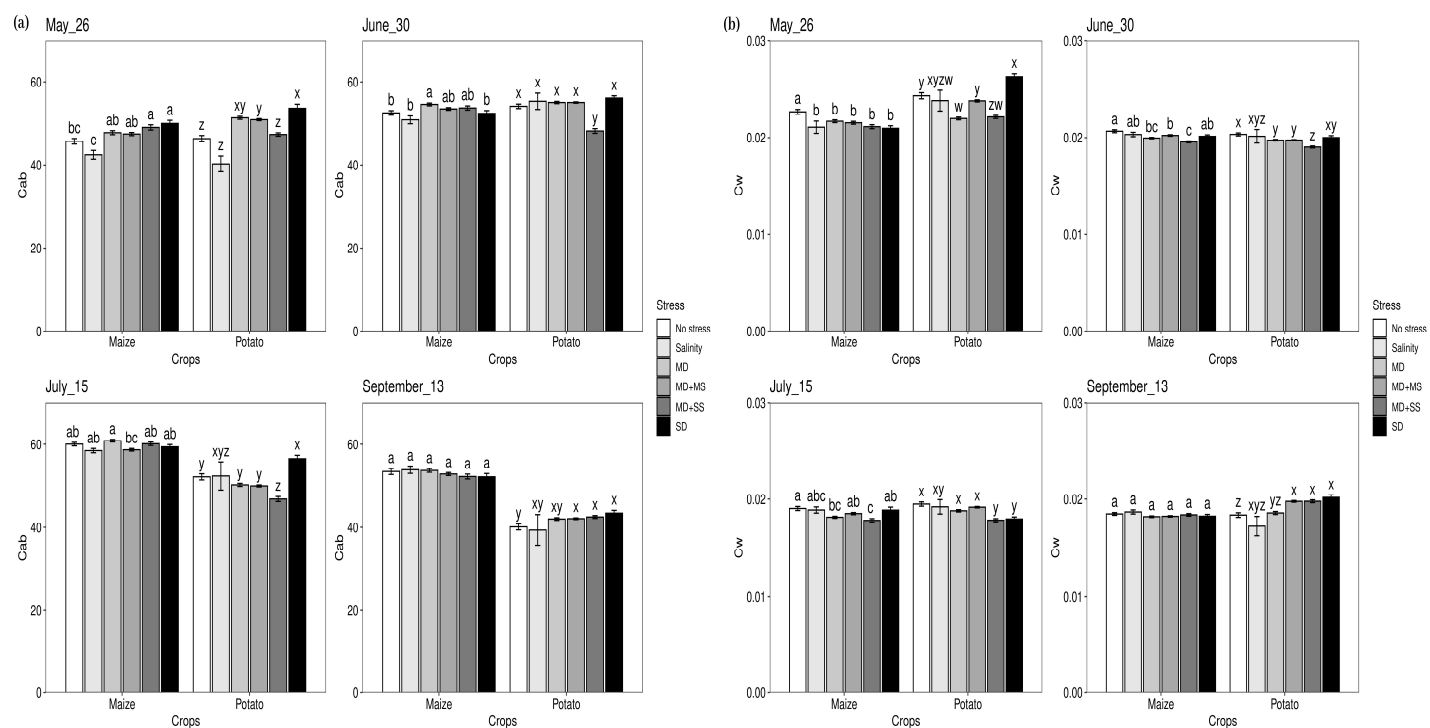

Figure 4. Trait expression of $\mathrm{Cab}$ and $\mathrm{Cw}$ under various stress conditions in May, June, July and September. Different letters in each panel indicate significant differences $(p<0.05)$. 


\section{Discussion}

In this study, we quantified the large-scale impacts of co-occurring drought and salinity on a variety of crop traits using satellite remote sensing. We observed that -in contrast to our expectations - the impacts of salinity were not highly pronounced at this scale, with most strong impacts originating due to drought stress during the 2018 drought. However, at specific moments in the growing season, salinity and/or the combined effects of salinity and drought pronouncedly affected individual crop traits. In this way, with increasing salinity driven by more intensive droughts, water allocation should not only be governed by the amount of water shortage, but also the salinity of the remaining water. In this paper, we provide the first evidence that those impacts can be monitored through remote sensing. This might provide a basis towards a monitoring system for multiple crops with multiple stresses as well as better governance policies to release this problem.

\subsection{Drought stress is more important than salinity stress in farmers' conditions}

The exacerbating effects of co-occurrent drought and salinity (Fig. 3 and Fig. 4) that we found are consistent with findings of small-scale experiments (e.g. greenhouses). Consistent with our results, synergistic effects of co-occurring water stress and salinity stress have been found on maize reproductive growth and grain formation in a field study (Liao et al., 2022). Spinach (Spinaciaoleracea L., cv. Racoon) yield decreased more under co-occurring water-salinity stress in comparison with separate water stress and salinity (Ors and Suarez, 2017). The co-occurring drought and salinity stress was more harmful to cotton root growth compared to their individual effects (Zhang et al., 2013). Moreover, the combined negative effect of drought and salinity stress on Panicum antidotale was stronger than that of single stress (Hussain et al., 2020). Our research showed that the outcomes of these small-scale experimental studies also apply to real large-scale environments, where different sources of variance are present. Specifically, we show that in real farmers' conditions, the co-occurrence of drought and salinity indeed can constitute a severe threat for crop growth.

In addition, we evaluated whether drought or salinity stress has more impact on crop performance. We observed that maize and potato were generally more sensitive to drought than salinity in this study (Fig. 3 and Fig. 4). This is consistent with results of previous studies that highlight that drought impacts are generally more detrimental than salinity stress for crops, e.g. for sesame (Sesamum indicum) (Harfi et al., 2016), Mentha pulegium L. (Azad et al., 2021), durum wheat (Sayar et al., 2010), grass pea (Tokarz et al., 2020), and sweet sorghum (Patane et al., 2013). However, given that the threshold of salinity at which crop damage occurs (according to the FAO guidelines (Ayers and Westcot, 1985)) was surpassed in all situations in which salinity stress was imposed (including in our study), we initially expected salinity to be a stronger explanatory variable than drought. As such, salinity impacts on crop performance (by the FAO) may have been overestimated. Indeed, in an experimental field situation in which drought stress was carefully avoided, higher thresholds of salinity-induced damage were observed for potato (van Straten et al., 2021).

In combination, the results from our study (supported by results from other studies) suggest that salinity particularly induces adverse effects when co-occurring with drought stress. Thus, the detrimental effect of single drought stress on crop growth is considered to be mitigated by salinity, which might be associated with the synergetic effect in carbon assimilation and osmotic adjustment by $\mathrm{Na}^{+}$and $\mathrm{Cl}^{-}$(Hussain et al., 2020).

\subsection{Drought and salinity stress differ between growth stages}

The responses to drought and salinity stress were different at different growth stages of the crops. This was expressed by the significant interactions between the effects of time and stress conditions for all of our crop responses (Table 1). We found that during the grain filling (maize) and tuber bulking phase (potato), the sensitivities of these crops are expressed 
distinctly in the non-harvested aboveground tissues (Fig. 3 and Fig.4), with clear differences in the remote sensing plant traits.

Given that we were not able to monitor the harvestable products, multiple mechanisms may explain these patterns. The relatively high leaf coverage (as related to LAI, FAPAR, and FVC) at saline and severe drought conditions at the end of the growing season may be an expression of a compensation process. Specifically, early and prolonged drought could have led to more assimilates allocated to non-harvestable potato parts for drought resistance since the number of tubers reduced (Jefferies, 1995;Schittenhelm et al., 2006). In that case, we should consider their higher leaf coverage at the end of the season a survival mechanism, rather than true drought tolerance, leading to reduced tuber yields (Daryanto et al., 2016b). Future studies that combine remote sensing with harvesting data may be able to evaluate this mechanism in more detail. In our study, different response patterns of maize and potato occurred to the different stresses over the growing season. This is consistent with previous studies focusing on the impact of drought and/or salinity onsets. For potato, it has been suggested that tuber yields particularly decreased when drought stress occurs during the vegetative and tuber initiation stages than during the tuber bulking stage (Wagg et al., 2021), although another study observed the reverse pattern (Daryanto et al., 2016b). For maize, on the other hand, drought seems to have the most detrimental impact during the maturation stage (Mi et al., 2018;Zhang et al., 2019), and the reproductive phase (Daryanto et al., 2017;Daryanto et al., 2016a). Considering, the additional co-varying factors within our 'real-life' study, it is very promising that we were able to detect similar effects. This suggests that we may use satellite remote sensing -albeit less spatially precise than e.g. sensing through drones- as a cost-effective early warning signal for detecting drought and salinity stress at moments during the growing season when differences in crop performance are still subtle.

\subsection{A multi-trait approach to understanding crop responses to stress}

In addition to being able to evaluate crop performance during multiple stages of the growing season (in contrast to most destructive methods), remote sensing also allows a multi-trait approach to better understand the mechanisms involved in crop responses. In our study, $\mathrm{Cab}$ and $\mathrm{Cw}$ had a response to drought and salinity distinct from LAI, FAPAR, and FVC, which showed a similar pattern (Fig. 3 and Fig. 4). Given that individual crop traits may differently respond to drought and salinity to reflect their stress resistance and tolerance strategies, the evaluation of these distinct responses may help understanding these strategies.

In this study, $\mathrm{Cw}$ was consistently lower in all drought and salinity treatments compared to no stress conditions in May, June and July. Indeed, this is a common response of plants in response to drought and salinity (e.g. Wen et al., 2020). In that respect, it is interesting that no decrease in $\mathrm{Cw}$ was observed at the end of the growing season, in October. Whether the phenomenon is related to the survival mechanism mentioned above or to the lower transpiration demands at the end of the season because of lower aboveground biomass, cannot be concluded from these data. Some evidence pointing to the survival mechanism is the finding (Ghosh et al., 2001; Levy, 1992) that the leaf dry matter increased for potato under drought/salinity stress (like in our study) while the dry matter of the tubers appeared to have a greater decline.

With respect to chlorophyll contents, we observed a decline in Cab at saline conditions, at the salinity treatment in May and the MS+SS treatment in June and July, while no decrease was observed in any of the treatments exposed to drought only. This indicates that while total leaf area was not (much) affected by salinity, the salinity did negatively affect crop performance. It has been reported that chlorophyll content in maize was significantly reduced upon salinity, along with other plant traits including plant height, shoot/root biomass, and leaf numbers (Fatima et al., 2021;Mahmood et al., 2021). 
Likewise, similar patterns were obtained in potato plants in saline soil (Efimova et al., 2018). Hence, this implies that soil salinity tends to negatively affect crop growth and restrict nutrient uptake.

\section{Conclusions}

In this study, we represent the first attempt to evaluate the effects of drought, salinity and their combination on crop traits in real-life conditions based on remote sensing information. Our approach gives new insights for monitoring multi-crop growth under co-occurring stresses at a large scale with high-resolution data. We found that while in general temporal patterns -reflecting crop growth dynamics- were stronger than effects of stress conditions, stress impacts depended on the time of the growing season. Furthermore, we also found that the temporal dynamics in crop responses to drought and salinity were different for maize vs. potato. In general, the five investigated traits were more negative affected by a combination of drought and salinity stress compared to individual stress. Meanwhile, both maize and potato responded more prominently to drought, thus demonstrating a stronger sensitivity, than to salinity. Specifically, LAI, FAPAR, and FVC dropped the most under severe drought stress conditions. Consequently, the proposed new approach poses a facilitated way for simultaneously monitoring the effect of drought and salinity on crops in large-scale agricultural applications.

Data availability. The drought map of the Netherlands in 2018 is retrieved from Chen et al. (2021). The topsoil salinity map of the Netherlands is retrieved from The Netherlands Hydrological Instrumentarium (NHI) (https://data.nhi.nu/). The crop map of the Netherlands in 2018 is retrieved from the Key Register of Parcels (BRP) of the Netherlands Enterprise Agency (https://www.pdok.nl/introductie/-/article/basisregistratie-gewaspercelen-brp-). All satellite scenes are downloaded from The Copernicus Open Access Hub (https://scihub.copernicus.eu/). The dataset relevant to this study is available upon request from the corresponding author.

Author contributions. Conceptualization, JT, PVB and WW; methodology, JT, QC, WW and PVB.; investigation, WW and QC; writing — original draft preparation, WW; writing—review and editing, PVB. and JT; supervision, PVB and JT All authors have read and agreed to the published version of the manuscript.

Competing interests. The authors declare no conflict of interest.

Financial support. This work was supported by the China Scholarship Council (CSC).

\section{References}

Asner, G. P., Scurlock, J. M. O., and Hicke, J. A.: Global synthesis of leaf area index observations: Implications for ecological and remote sensing studies, Glob. Ecol. Biogeogr., 12, 191-205, https://doi.org/10.1046/j.1466822X.2003.00026.x, 2003.

Ayers, R. S., and Westcot, D. W.: Water quality for agriculture, Food and Agriculture Organization of the United Nations Rome, 1985.

Azad, N., Rezayian, M., Hassanpour, H., Niknam, V., and Ebrahimzadeh, H.: Physiological mechanism of salicylic acid in mentha pulegium 1. Under salinity and drought stress, Braz. J. Bot., 44, 359-369, https://doi.org/10.1007/s40415-021-00706-y, 2021.

Boussetta, S., Balsamo, G., Beljaars, A., Kral, T., and Jarlan, L.: Impact of a satellite-derived leaf area index monthly climatology in a global numerical weather prediction model, Int. J. Remote Sens., 34, 3520-3542, https://doi.org/10.1080/01431161.2012.716543, 2012.

Bowman, W. D.: The relationship between leaf water status, gas-exchange, and spectral reflectance in cotton leaves, 
Remote Sens. Environ., 30, 249-255, https://doi.org/10.1016/0034-4257(89)90066-7, 1989.

'Storm duurt dagen, droogte duurt maanden': https://www.rijkswaterstaat.n1/nieuws/archief/2018/08/storm-duurt-dagendroogte-duurt-maanden, 2018.

Chen, Q., Timmermans, J., Wen, W., and van Bodegom, P. M.: A multi-metric assessment of drought vulnerability across different vegetation types using high resolution remote sensing, Sci. Total Environ., 2021. (Under review)

Corwin, D. L.: Climate change impacts on soil salinity in agricultural areas, Eur. J. Soil Sci., 72, 842-862, https://doi.org/10.1111/ejss.13010, 2020.

Croft, H., Chen, J. M., Luo, X., Bartlett, P., Chen, B., and Staebler, R. M.: Leaf chlorophyll content as a proxy for leaf photosynthetic capacity, Glob. Change Biol., 23, 3513-3524, https://doi.org/10.1111/gcb.13599, 2017.

Daryanto, S., Wang, L., and Jacinthe, P. A.: Global synthesis of drought effects on maize and wheat production, PLoS One, 11, e0156362, https://doi.org/10.1371/journal.pone.0156362, 2016a.

Daryanto, S., Wang, L. X., and Jacinthe, P. A.: Drought effects on root and tuber production: A meta-analysis, Agric. Water Manag., 176, 122-131, https://doi.org/10.1016/j.agwat.2016.05.019, 2016b.

Daryanto, S., Wang, L. X., and Jacinthe, P. A.: Global synthesis of drought effects on cereal, legume, tuber and root crops production: A review, Agric. Water Manag., 179, 18-33, https://doi.org/10.1016/j.agwat.2016.04.022, 2017.

Dunn, R. J. H., Stanitski, D. M., Gobron, N., Willett, K. M., Ades, M., Adler, R., Allan, R., Allan, R. P., Anderson, J., Argüez, A., Arosio, C., Augustine, J. A., Azorin-Molina, C., Barichivich, J., Barnes, J., Beck, H. E., Becker, A., Bellouin, N., Benedetti, A., Berry, D. I., Blenkinsop, S., Bock, O., Bosilovich, M. G., Boucher, O., Buehler, S. A., Carrea, L., Christiansen, H. H., Chouza, F., Christy, J. R., Chung, E. S., Coldewey-Egbers, M., Compo, G. P., Cooper, O. R., Covey, C., Crotwell, A., Davis, S. M., de Eyto, E., de Jeu, R. A. M., VanderSat, B. V., DeGasperi, C. L., Degenstein, D., Di Girolamo, L., Dokulil, M. T., Donat, M. G., Dorigo, W. A., Durre, I., Dutton, G. S., Duveiller, G., Elkins, J. W., Fioletov, V. E., Flemming, J., Foster, M. J., Frey, R. A., Frith, S. M., Froidevaux, L., Garforth, J., Gupta, S. K., Haimberger, L., Hall, B. D., Harris, I., Heidinger, A. K., Hemming, D. L., Ho, S.-p., Hubert, D., Hurst, D. F., Hüser, I., Inness, A., Isaksen, K., John, V., Jones, P. D., Kaiser, J. W., Kelly, S., Khaykin, S., Kidd, R., Kim, H., Kipling, Z., Kraemer, B. M., Kratz, D. P., La Fuente, R. S., Lan, X., Lantz, K. O., Leblanc, T., Li, B., Loeb, N. G., Long, C. S., Loyola, D., Marszelewski, W., Martens, B., May, L., Mayer, M., McCabe, M. F., McVicar, T. R., Mears, C. A., Menzel, W. P., Merchant, C. J., Miller, B. R., Miralles, D. G., Montzka, S. A., Morice, C., Mühle, J., Myneni, R., Nicolas, J. P., Noetzli, J., Osborn, T. J., Park, T., Pasik, A., Paterson, A. M., Pelto, M. S., Perkins-Kirkpatrick, S., Pétron, G., Phillips, C., Pinty, B., Po-Chedley, S., Polvani, L., Preimesberger, W., Pulkkanen, M., Randel, W. J., Rémy, S., Ricciardulli, L., Richardson, A. D., Rieger, L., Robinson, D. A., Rodell, M., Rosenlof, K. H., Roth, C., Rozanov, A., Rusak, J. A., Rusanovskaya, O., Rutishäuser, T., Sánchez-Lugo, A., Sawaengphokhai, P., Scanlon, T., Schenzinger, V., Schladow, S. G., Schlegel, R. W., Schmid, M. E., Selkirk, H. B., Sharma, S., Shi, L., Shimaraeva, S. V., Silow, E. A., Simmons, A. J., Smith, C. A., Smith, S. L., Soden, B. J., Sofieva, V., Sparks, T. H., Stackhouse, P. W., Steinbrecht, W., Streletskiy, D. A., Taha, G., Telg, H., Thackeray, S. J., Timofeyev, M. A., Tourpali, K., Tye, M. R., van der A, R. J., van der Schalie, R. V. B. V., van der SchrierW. Paul, G., van der Werf, G. R., Verburg, P., Vernier, J.-P., Vömel, H., Vose, R. S., Wang, R., Watanabe, S. G., Weber, M., Weyhenmeyer, G. A., Wiese, D., Wilber, A. C., Wild, J. D., Wong, T., Woolway, R. I., Yin, X., Zhao, L., Zhao, G., Zhou, X., Ziemke, J. R., and Ziese, M.: Global climate-state of the climate in 2019, Bull. Amer. Meteor.0003-0007 1520-0477, S9-S128, 2020.

Efimova, M. V., Kolomeichuk, L. V., Boyko, E. V., Malofii, M. K., Vidershpan, A. N., Plyusnin, I. N., Golovatskaya, I. F., Murgan, O. K., and Kuznetsov, V. V.: Physiological mechanisms of solanum tuberosum 1. Plants' tolerance to chloride salinity, Russ. J. Plant Physiol., 65, 394-403, https://doi.org/10.1134/S1021443718030020, 2018.

Fang, H., Baret, F., Plummer, S., and Schaepman-Strub, G.: An overview of global leaf area index (lai): Methods, products, validation, and applications, Rev. Geophys., 57, 739-799, https://doi.org/10.1029/2018RG000608, 2019.

FAO, I., UNICEF, WFP and WHO: The state of food security and nutrition in the world 2020, FAO, Rome978-92-5132901-6, 2020.

Fatima, A., Hussain, S., Hussain, S., Ali, B., Ashraf, U., Zulfiqar, U., Aslam, Z., Al-Robai, S. A., Alzahrani, F. O., Hano, C., and El-Esawi, M. A.: Differential morphophysiological, biochemical, and molecular responses of maize hybrids to salinity and alkalinity stresses, Agronomy-Basel, 11, 1150, https://doi.org/10.3390/agronomy11061150, 2021.

Gerhards, M., Schlerf, M., Mallick, K., and Udelhoven, T.: Challenges and future perspectives of multi-/hyperspectral thermal infrared remote sensing for crop water-stress detection: A review, Remote Sens., 11, 1240-1264, https://doi.org/10.3390/rs11101240, 2019.

Gitelson, A. A., Vina, A., Ciganda, V., Rundquist, D. C., and Arkebauer, T. J.: Remote estimation of canopy chlorophyll content in crops, Geophys. Res. Lett., 32, L08403, https://doi.org/10.1029/2005GL022688, 2005.

Godfray, H. C., Beddington, J. R., Crute, I. R., Haddad, L., Lawrence, D., Muir, J. F., Pretty, J., Robinson, S., Thomas, S. M., and Toulmin, C.: Food security: The challenge of feeding 9 billion people, Science, 327, 812-818, https://doi.org/10.1126/science.1185383, 2010.

Harfi, M. E., Hanine, H., Rizki, H., Latrache, H., and Nabloussi, A.: Effect of drought and salt stresses on germination and early seedling growth of different color-seeds of sesame (sesamum indicum), Int. J. Agric. Biol., 18, 1088-1094, 
https://doi.org/10.17957/ijab/15.0145, 2016.

Homolova, L., Maenovsky, Z., Clevers, J. G. P. W., Garcia-Santos, G., and Schaeprnan, M. E.: Review of optical-based remote sensing for plant trait mapping, Ecol. Complex., 15, 1-16, https://doi.org/10.1016/j.ecocom.2013.06.003, 2013.

Hussain, T., Koyro, H. W., Zhang, W., Liu, X., Gul, B., and Liu, X.: Low salinity improves photosynthetic performance in panicum antidotale under drought stress, Front. Plant Sci., 11, 481, https://doi.org/10.3389/fpls.2020.00481, 2020.

Jarlan, L., Balsamo, G., Lafont, S., Beljaars, A., Calvet, J. C., and Mougin, E.: Analysis of leaf area index in the ecmwf land surface model and impact on latent heat and carbon fluxes: Application to west africa, J. Geophys. Res. Atmos., 113, D24117, https://doi.org/10.1029/2007jd009370, 2008.

Jefferies, R.: Physiology of crop response to drought, in: Potato ecology and modelling of crops under conditions limiting growth, Springer, 61-74, 1995 .

Jones, E., and van Vliet, M. T. H.: Drought impacts on river salinity in the southern us: Implications for water scarcity, Sci. Total Environ., 644, 844-853, https://doi.org/10.1016/j.scitotenv.2018.06.373, 2018.

Kriston-Vizi, J., Umeda, M., and Miyamoto, K.: Assessment of the water status of mandarin and peach canopies using visible multispectral imagery, Biosyst. Eng., 100, 338-345, https://doi.org/10.1016/j.biosystemseng.2008.04.001, 2008.

Liang, S. L. W., J. D.: Chapter 11 - fraction of absorbed photosynthetically active radiation, in: Advanced remote sensing (second edition), edited by: Liang, S., and Wang, J., Academic Press, 447-476, 2020.

Liao, Q., Gu, S. J., Kang, S. Z., Du, T. S., Tong, L., Wood, J. D., and Ding, R. S.: Mild water and salt stress improve water use efficiency by decreasing stomatal conductance via osmotic adjustment in field maize, Sci. Total Environ., 805, https://doi.org/10.1016/j.scitotenv.2021.150364, 2022.

Mahmood, U., Hussain, S., Hussain, S., Ali, B., Ashraf, U., Zamir, S., Al-Robai, S. A., Alzahrani, F. O., Hano, C., and ElEsawi, M. A.: Morpho-physio-biochemical and molecular responses of maize hybrids to salinity and waterlogging during stress and recovery phase, Plants (Basel), 10, https://doi.org/10.3390/plants10071345, 2021.

Masante D., B. P., McCormick N.: Drought in central-northern europe - august 2018, Report of the Copernicus European Drought Observatory (EDO) and Emergency Response Coordination Center (ERCC) Analytical Team 1-13, 2018.

McKee, T. B., Doesken, N. J., and Kleist, J.: The relationship of drought frequency and duration to time scales, Proceedings of the 8th Conference on Applied Climatology, 1993, 179-183,

Mi, N., Cai, F., Zhang, Y. S., Ji, R. P., Zhang, S. J., and Wang, Y.: Differential responses of maize yield to drought at vegetative and reproductive stages, Plant Soil Environ., 64, 260-267, https://doi.org/10.17221/141/2018-Pse, 2018.

Mulder, M., Hack-ten Broeke, M., Bartholomeus, R., van Dam, J., Heinen, M., van Bakel, J., Walvoort, D., Kroes, J., Hoving, I., and Holshof, G.: Waterwijzer landbouw: Instrumentarium voor kwantificeren van effecten van waterbeheer en klimaat op landbouwproductie, 2018-48, Stowa, 2018.

Ors, S., and Suarez, D. L.: Spinach biomass yield and physiological response to interactive salinity and water stress, Agric. Water Manag., 190, 31-41, https://doi.org/10.1016/j.agwat.2017.05.003, 2017.

Patane, C., Saita, A., and Sortino, O.: Comparative effects of salt and water stress on seed germination and early embryo growth in two cultivars of sweet sorghum, J. Agron. Crop Sci., 199, 30-37, https://doi.org/10.1111/j.1439037X.2012.00531.x, 2013.

Rozema, J., and Flowers, T.: Ecology. Crops for a salinized world, Science, 322, 1478-1480, https://doi.org/10.1126/science.1168572, 2008.

Sayar, R., Bchini, H., Mosbahi, M., and Khemira, H.: Response of durum wheat (triticum durum desf.) growth to salt and drought stresses, Czech J. Genet. Plant. Breed., 46, 54-63, https://doi.org/10.17221/85/2009-CJGPB, 2010.

Schittenhelm, S., Sourell, H., and Lopmeier, F. J.: Drought resistance of potato cultivars with contrasting canopy architecture, Eur. J. Agron., 24, 193-202, https://doi.org/10.1016/j.eja.2005.05.004, 2006.

Schwalm, C. R., Anderegg, W. R. L., Michalak, A. M., Fisher, J. B., Biondi, F., Koch, G., Litvak, M., Ogle, K., Shaw, J. D., Wolf, A., Huntzinger, D. N., Schaefer, K., Cook, R., Wei, Y., Fang, Y., Hayes, D., Huang, M., Jain, A., and Tian, H.: Global patterns of drought recovery, Nature, 548, 202-205, https://doi.org/10.1038/nature23021, 2017.

Shinozaki, K., Uemura, M., Bailey-Serres, J., Bray, E., and Weretilnyk, E.: Responses to abiotic stress, Biochemistry and molecular biology of plants, Wiley Blackwell, 1051-1100 pp., 2015.

Steidle Neto, A. J., Lopes, D. d. C., Silva, T. G. F. d., Ferreira, S. O., and Grossi, J. A. S.: Estimation of leaf water content in sunflower under drought conditions by means of spectral reflectance, Eng. Agric. Environ. Food, 10, 104-108, https://doi.org/10.1016/j.eaef.2016.11.006, 2017.

Stuyt, L. C. P. M., Blom-Zandstra, M., \& Kselik, R. A. L. : Inventarisatie en analyse zouttolerantie van landbouwgewassen op basis van bestaande gegevens, Wageningen environmental research rapport, Wageningen Environmental Research, 2016.

Tokarz, B., Wójtowicz, T., Makowski, W., Jędrzejczyk, R. J., and Tokarz, K. M.: What is the difference between the response of grass pea (lathyrus sativus 1.) to salinity and drought stress? - a physiological study, Agronomy, 10, 833, https://doi.org/10.3390/agronomy10060833, 2020.

Trenberth, K. E., Dai, A., van der Schrier, G., Jones, P. D., Barichivich, J., Briffa, K. R., and Sheffield, J.: Global warming 
and changes in drought, Nat. Clim. Chang., 4, 17-22, https://doi.org/10.1038/nclimate2067, 2013.

Tucker, C. J.: Red and photographic infrared linear combinations for monitoring vegetation, Remote Sens. Environ., 8, 127-150, https://doi.org/10.1016/0034-4257(79)90013-0, 1979.

van Straten, G., Bruning, B., de Vos, A. C., González, A. P., Rozema, J., and van Bodegom, P. M.: Estimating cultivarspecific salt tolerance model parameters from multi-annual field tests for identification of salt tolerant potato cultivars, Agric. Water Manag., 252, https://doi.org/10.1016/j.agwat.2021.106902, 2021.

Vereecken, H., Weihermuller, L., Jonard, F., and Montzka, C.: Characterization of crop canopies and water stress related phenomena using microwave remote sensing methods: A review, Vadose Zone J., 11, vzj2011.0138ra, https://doi.org/10.2136/vzj2011.0138ra, 2012.

Wagg, C., Hann, S., Kupriyanovich, Y., and Li, S.: Timing of short period water stress determines potato plant growth, yield and tuber quality, Agric. Water Manag., 247, https://doi.org/10.1016/j.agwat.2020.106731, 2021.

Wang, J. L., Huang, X. J., Zhong, T. Y., and Chen, Z. G.: Climate change impacts and adaptation for saline agriculture in north jiangsu province, china, Environ. Sci. Policy, 25, 83-93, https://doi.org/10.1016/j.envsci.2012.07.011, 2013.

Weiss, M., and Baret, F.: S2toolbox level 2 products: Lai, fapar, fcover, version 1.1, ESA Contract nr 4000110612/14/IBG, 52, 2016.

Weiss, M., Jacob, F., and Duveiller, G.: Remote sensing for agricultural applications: A meta-review, Remote Sens. Environ., 236, 111402, https://doi.org/10.1016/j.rse.2019.111402, 2020.

Wen, W., Timmermans, J., Chen, Q., and van Bodegom, P. M.: A review of remote sensing challenges for food security with respect to salinity and drought threats, Remote Sens., 13, https://doi.org/10.3390/rs13010006, 2020.

Wengert, M., Piepho, H. P., Astor, T., Grass, R., Wijesingha, J., and Wachendorf, M.: Assessing spatial variability of barley whole crop biomass yield and leaf area index in silvoarable agroforestry systems using uav-borne remote sensing, Remote Sens., 13, 2751, https://doi.org/10.3390/rs13142751, 2021.

Yang, L., Jia, K., Liang, S., Liu, M., Wei, X., Yao, Y., Zhang, X., and Liu, D.: Spatio-temporal analysis and uncertainty of fractional vegetation cover change over northern china during 2001-2012 based on multiple vegetation data sets, Remote Sens., 10, https://doi.org/10.3390/rs10040549, 2018.

Zhang, F., Zhou, G. S., and Nilsson, C.: Remote estimation of the fraction of absorbed photosynthetically active radiation for a maize canopy in northeast china, J. Plant Ecol., 8, 429-435, https://doi.org/10.1093/jpe/rtu027, 2015.

Zhang, H., Han, M., Comas, L. H., DeJonge, K. C., Gleason, S. M., Trout, T. J., and Ma, L.: Response of maize yield components to growth stage - based deficit irrigation, Agron. J., 111, 3244-3252, https://doi.org/10.2134/agronj2019.03.0214, 2019.

Zhang, L., Zhang, G., Wang, Y., Zhou, Z., Meng, Y., and Chen, B.: Effect of soil salinity on physiological characteristics of functional leaves of cotton plants, J. Plant Res., 126, 293-304, https://doi.org/10.1007/s10265-012-0533-3, 2013.

Zhu, X., Wang, T. J., Skidmore, A. K., Darvishzadeh, R., Niemann, K. O., and Liu, J.: Canopy leaf water content estimated using terrestrial lidar, Agric. For. Meteorol., 232, 152-162, https://doi.org/10.1016/j.agrformet.2016.08.016, 2017. 